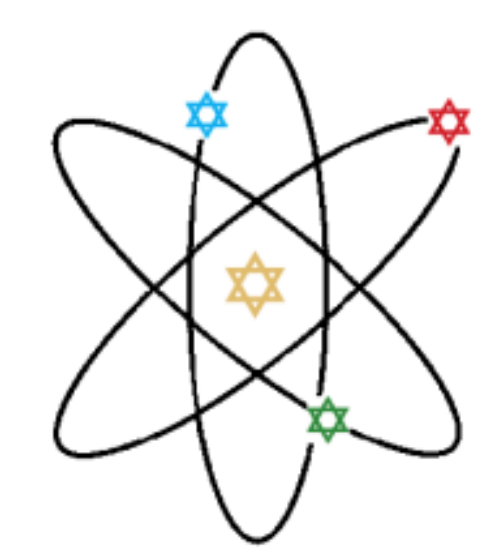

\title{
STEM Engagement in K-8 Private Jewish Day Schools
}

\author{
Joshua S. Katz
}

DuPont Nutrition \& Biosciences

March 22, 2020

Joshua.katz@dupont.com A DUDNT. 


\section{The STEM Squeeze}

A Day at Kohelet Yeshiva

A representative model for the Jewish Day School schedule

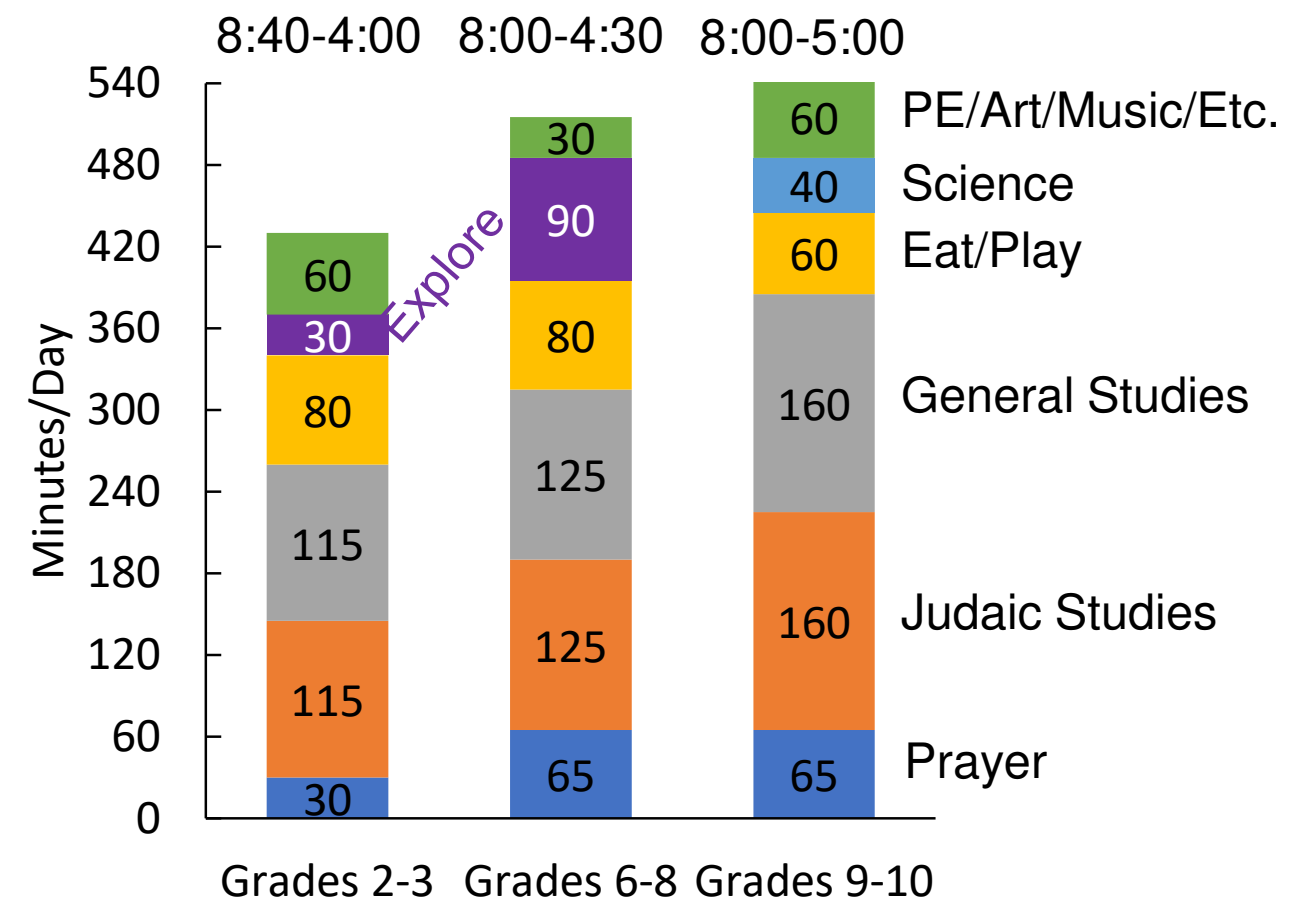

Days are long with a dual curriculum

Prioritization must occur across academic subjects

With more subjects in the curriculum, statistics dictate fewer students will personally prioritize STEM

Division of time varies by school, community, prioritization of values, and, religious outlook 


\section{There is a long history of Jews and Science}

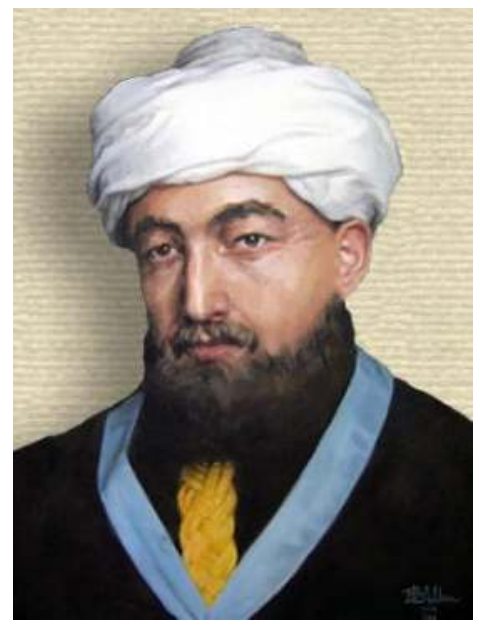

"Astrology is a disease, not a science... It is a tree under the shadow of which all sorts of superstitions thrive. ... Only fools and charlatans lend value to it." - Rabbi Moses ben Maimon (Maimonides), 1195.

"Science without religion is lame, religion without science is blind." Albert Einstein

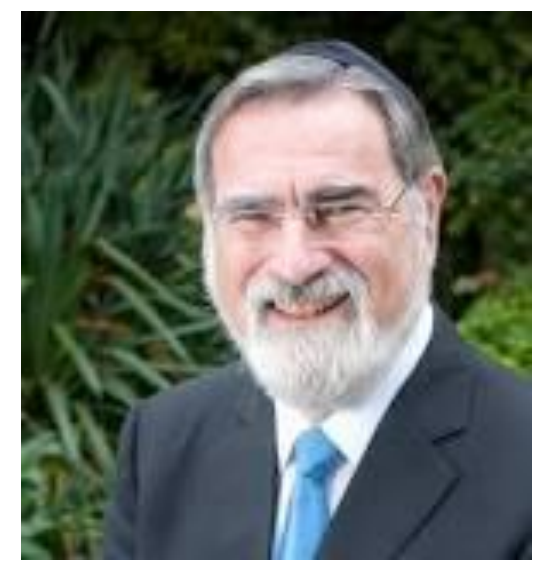

"If science is about the world that is, and religion is about the world that ought to be, then religion needs science because we cannot apply God's will to the world if we do not understand the world...By the same token, science needs religion...for each fresh item of
knowledge... raises the question of how it should be used" - Rabbi the same token, science needs religion...for each fresh item of
knowledge... raises the question of how it should be used" - Rabbi Lord Jonathan Sacks

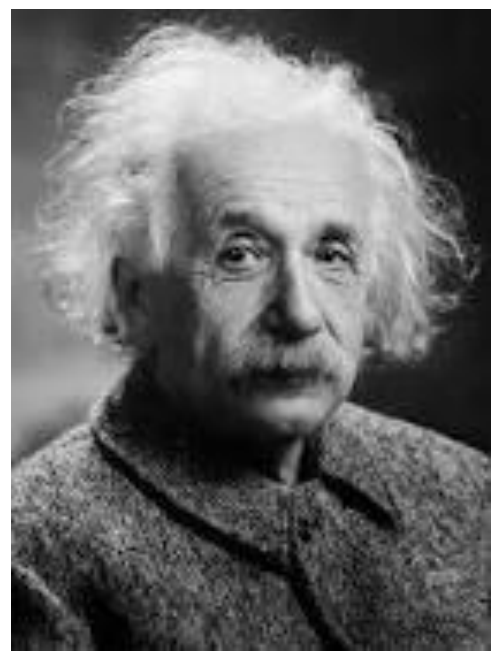




\section{Science and Judaism Complement Each Other}

- How can the themes of each be interwoven to inform and enhance the other?

- How can these themes be integrated into age-appropriate activities?

-What lessons can be learned that can be leveraged to broader educational needs? 


\section{Weaving science into religious and cultural themes}

- "Dip apples in honey for a sweet New Year"

- Hidden matza

- The miracle of oil

- Salt, water, buoyancy, and water purification

- Ancient dyes, color, and significant numbers 


\section{Dip the apples in the honey for a sweet New Year What makes honey unique?}

Science:

- Solids vs liquid sugars

- White vs colored sugars

- Viscosities

- Tastes

- Source of sugar

Religious

- Connection to Jewish New Year

- Connection to Land of Israel ("Land flowing with milk and honey.")

- Honey is the only food that is kosher to eat yet comes from a non-kosher animal.
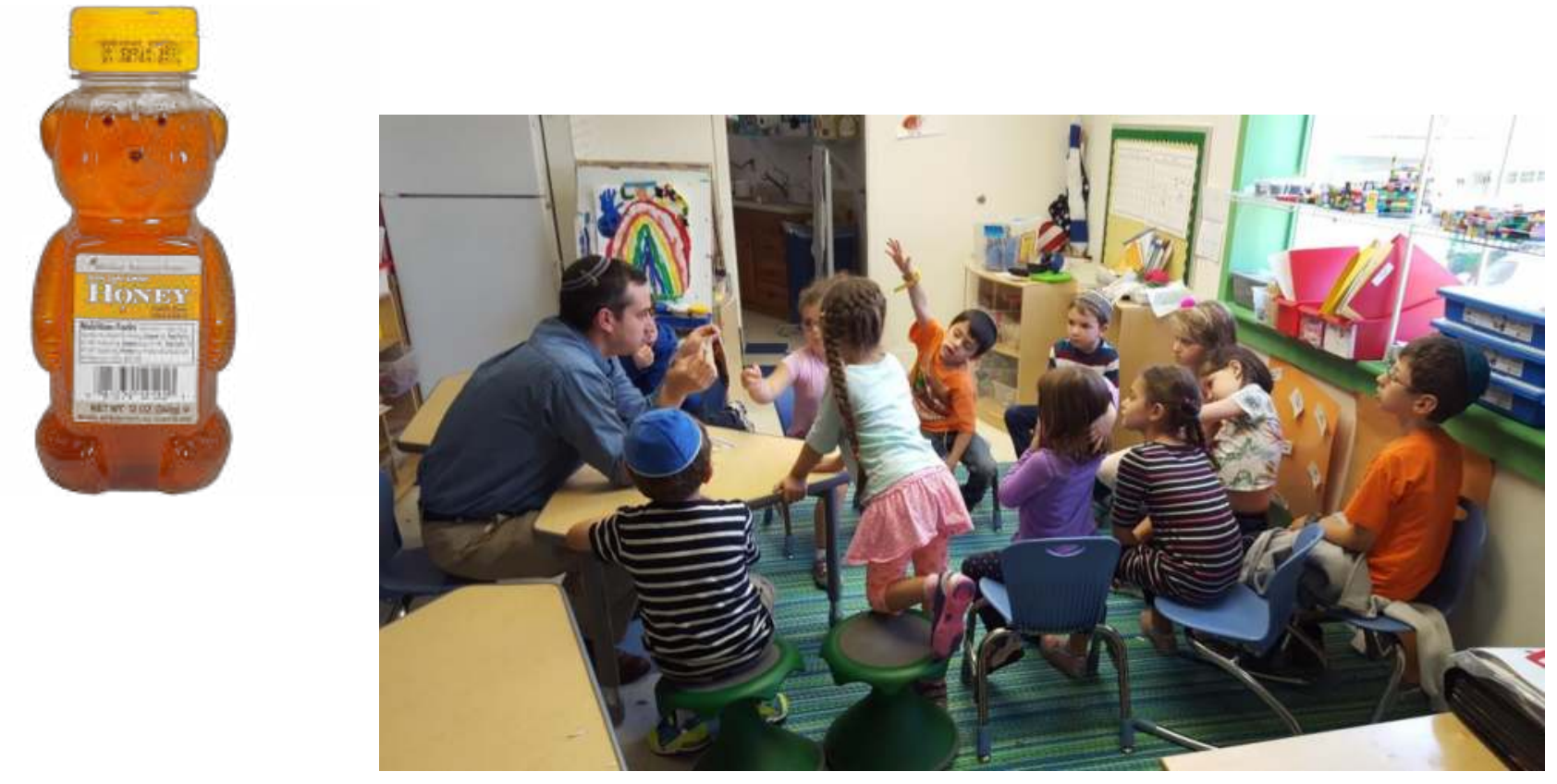


\section{The magically appearing afikoman}

What happens when you try to combine oil and water?

Science:

- Oil and water separations

- Materials of construction for artistic supplies
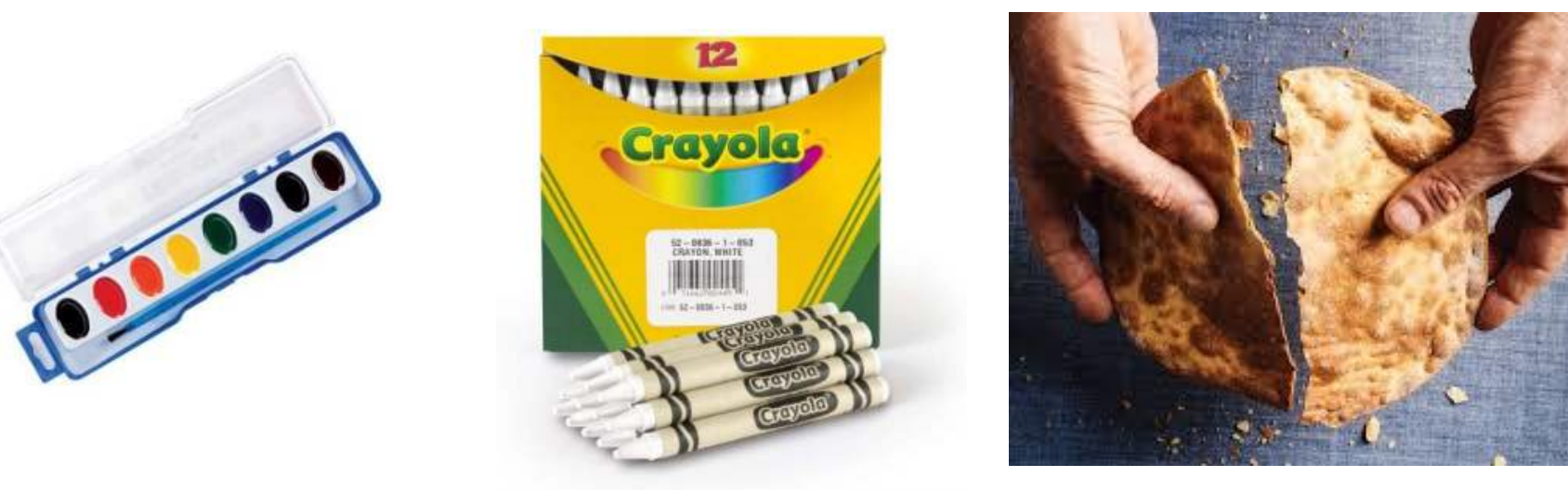

- Artistic expression

Religious:

- Connection point to Passover seder

- Reinforce lessons being taught at this time of year.

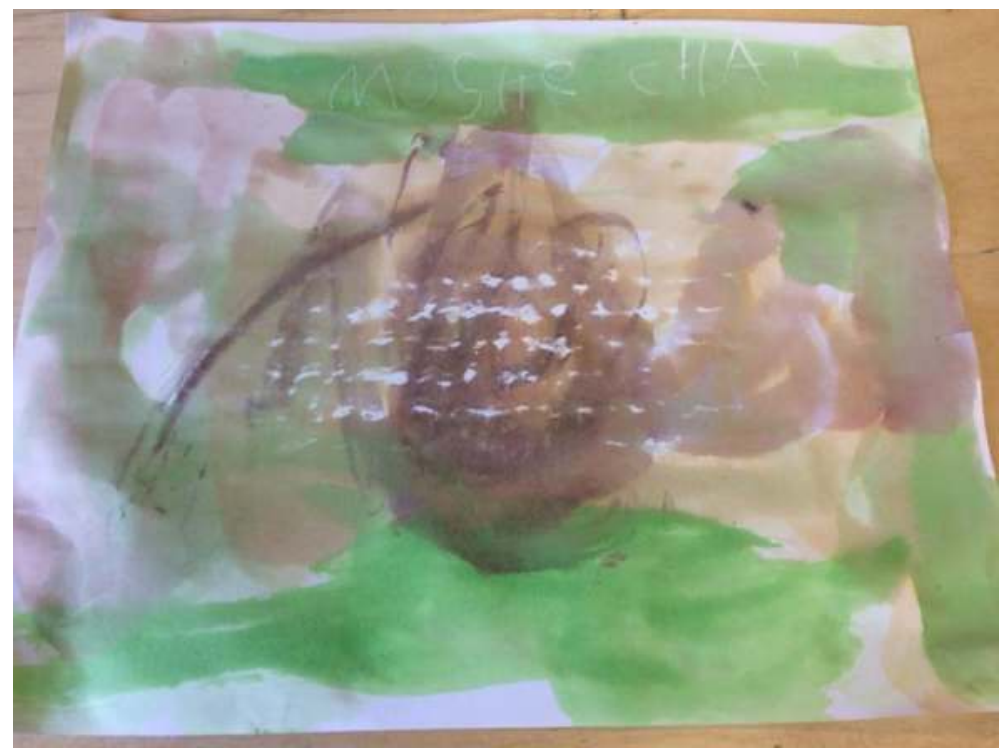




\section{One jug of oil lasted for eight nights.}

\section{Fats, oils, and fire}

Science:

- States of matter - solids and liquids

- Melting and freezing, phase transitions

- Elements of burning - fuel, oxygen, heat

- Fats vs hydrophiles

- Sources of oils - animal, vegetable

Religious:

- Chanukah oil burning for 8 nights

- Weekly lighting of Sabbath candles

- Permitted and non-permitted oils for kindling lights (Talmud)
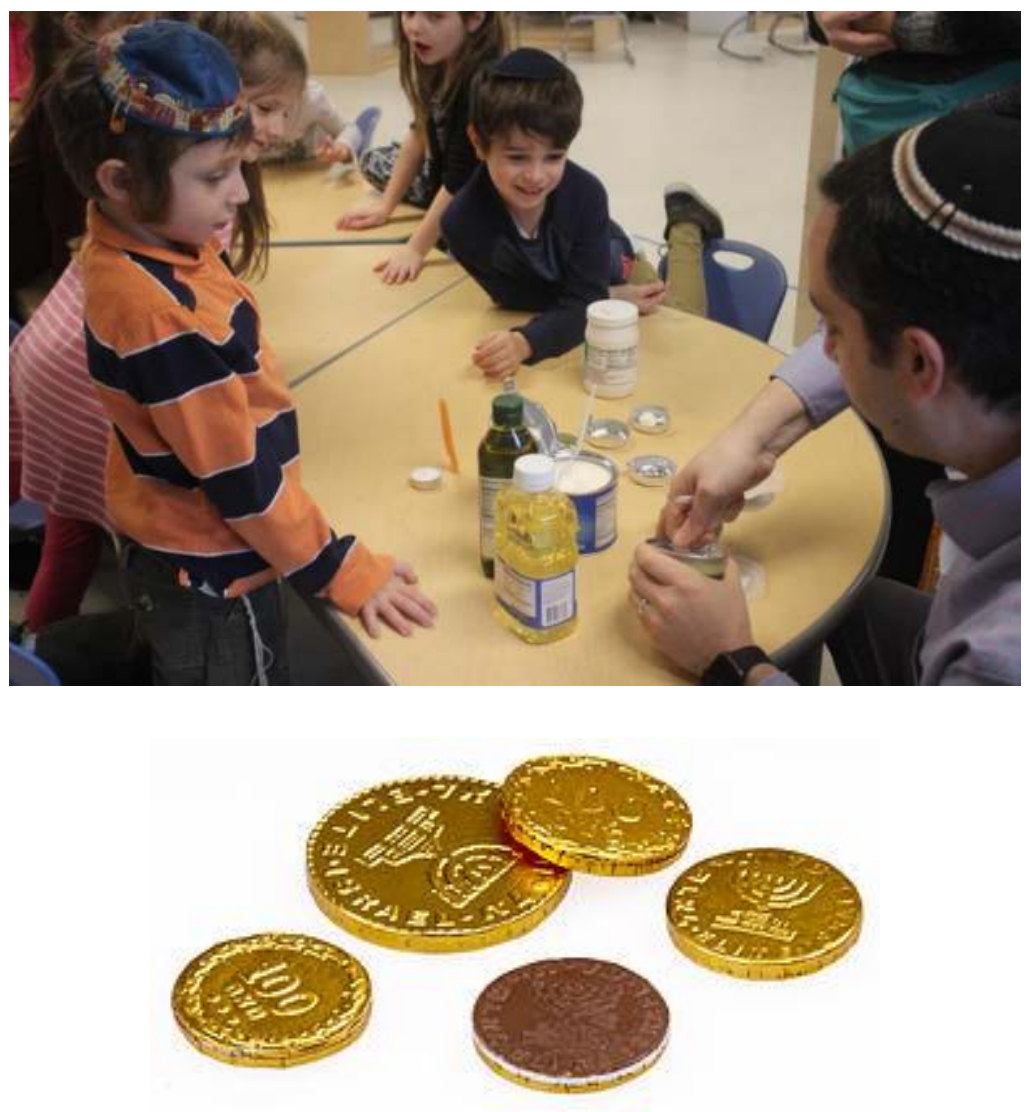


\section{The Red Sea-Dead Sea Conveyance Salt, Water, Buoyancy, and Desalination}

Science:

- Buoyancy caused by salination

- Measurement units

- Density

- Desalination technology

- Water scarcity

- Water recycling

- Outer space

Religious/Cultural:

- Israel had (at the time) the largest desalination plant in the world

- Israeli collaboration with neighboring countries

- Israeli technology development - drip irrigation, GMO's

- Dead Sea and Red Sea resorts

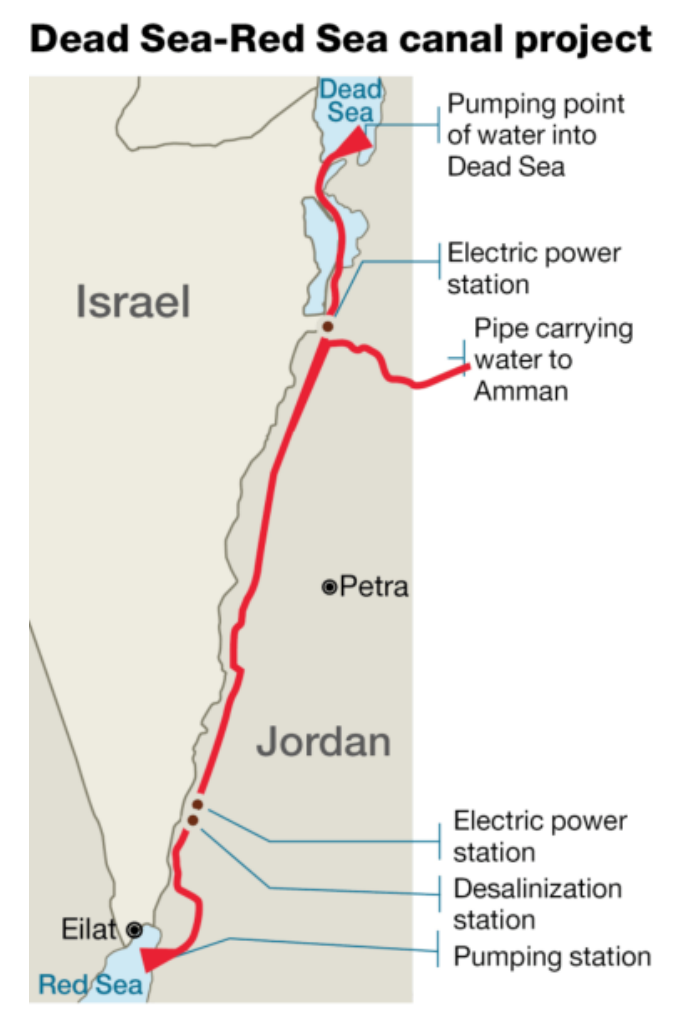

Haaretz.com

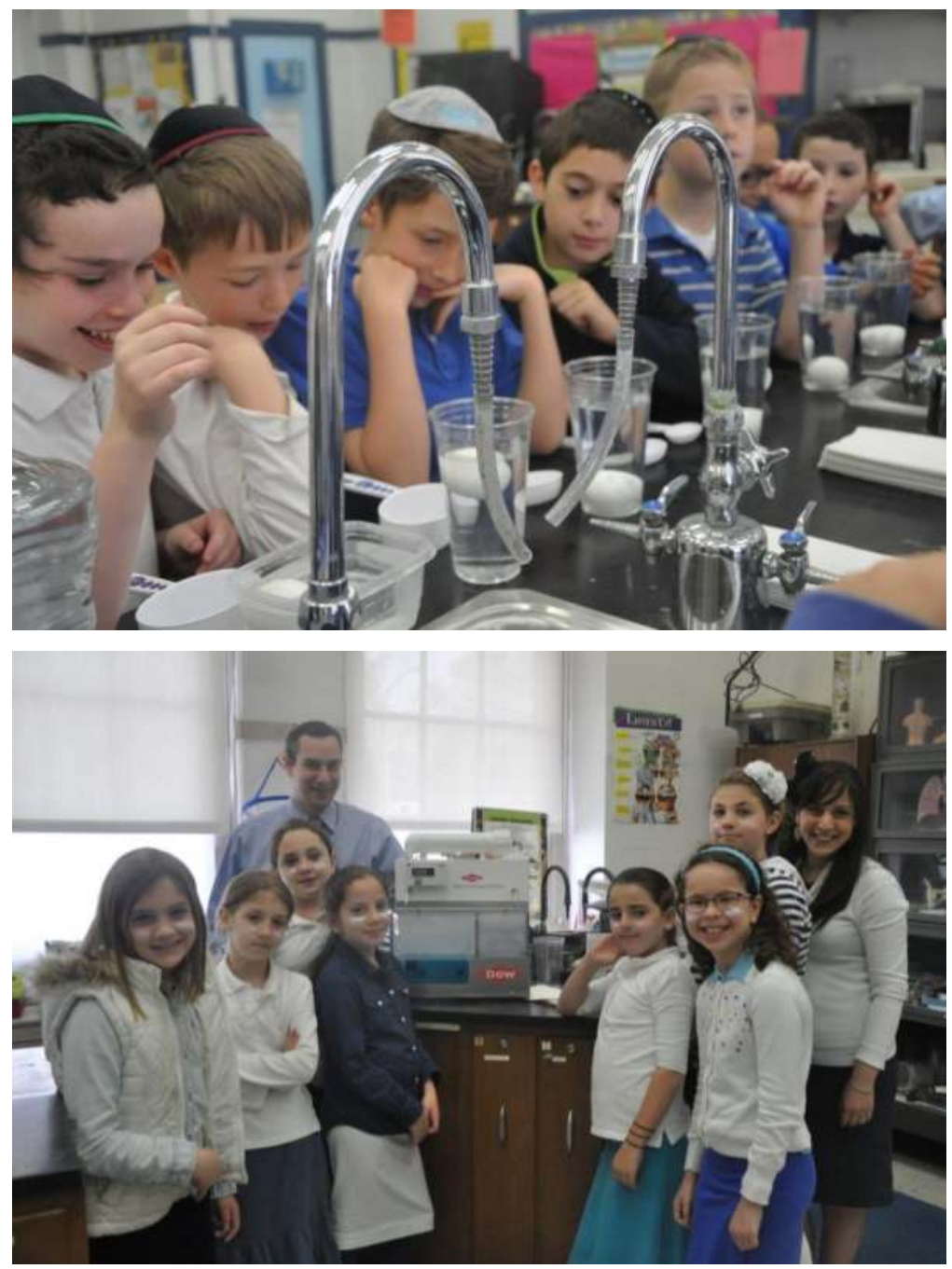




\section{"And you shall attach fringes to the corners of your garments.... with a thread of techelet"}

Color, Significant Numbers, and Religious Practice

Science:

- Chemical dyeing

- Aromaticity and resonance, redox chemistry

- Electromagnetic spectrum

- Color absorption and reflectance

- Spectroscopy

- Regression analysis

Religious:

- Talmudic discourse

- Rabbinic commentaries

- Degrees of stringencies

- Ancient social orders

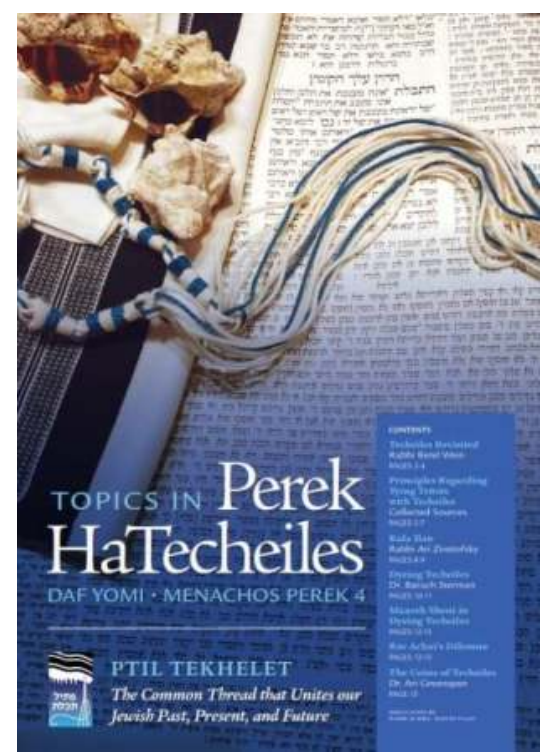

Ptil Tekhelet Pamphlet

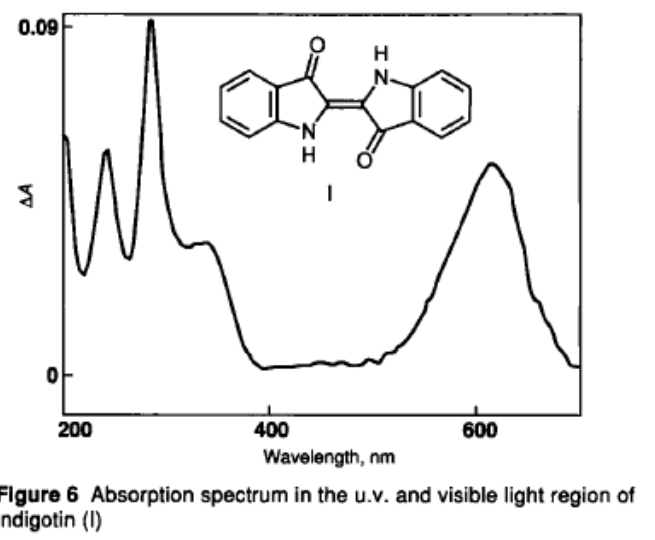

Wouters and Verhecken, JSDC, Vol 107, 1991, 266-269

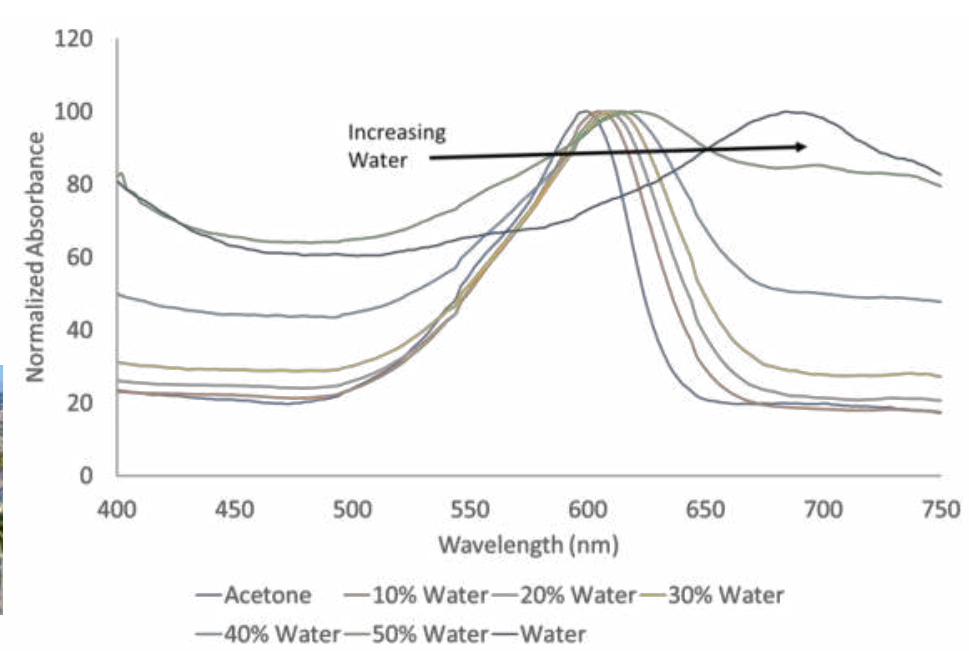




\section{Learnings}

- The lessons give the kids a tangible connection to the science and religion. Engage all 5 senses.

- For the (more) religious-minded kids, the lesson gives them a new access point to science. For the science-oriented kids, the lesson gives them a new access point to religion.

- Lessons being taught by a religiously-relatable scientist adult provides a positive role model experience for the students. It gives them a way to visualize themselves as scientists. 


\section{Acknowledgements}

- Caskey Torah Academy

- Rabbi Isaac Entin, Rabbi Zecharia Weitz, Elana Obstfeld, Rebecca Sasson

- Kohelet Yeshiva

- Becky Troodler, Rabbi Dr. Gil Perl, Rabbi David Wilensky, Dr. Jeremy Sullivan, Rachael Simon, Aria Wood, Jaimie Fuller, Diane Weintraub

- Ptil Tekhelet

- Baruch Sturman

- Photo Credits:

- Tanya Libesman, Michal Twersky
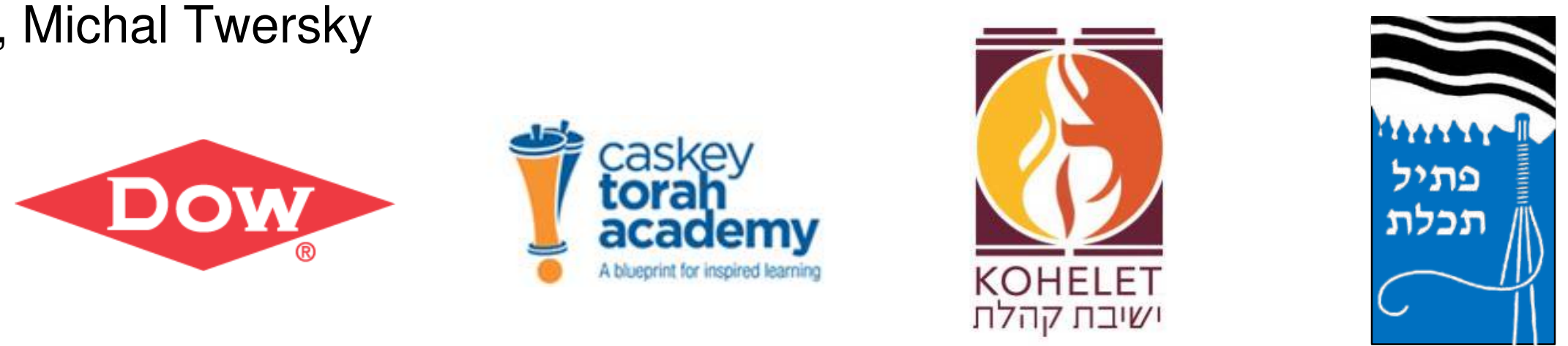


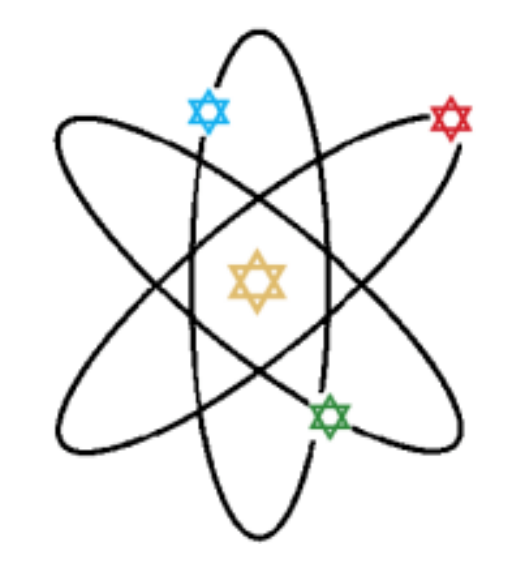

\title{
Thank You!
}

\author{
Joshua S. Katz
}

DuPont Nutrition \& Biosciences

Joshua.katz@dupont.com 